\title{
HDliveFlow with HDlive Silhouette Mode for Diagnosis of Persistent Right Umbilical Vein and Single Umbilical Artery
}

\author{
${ }^{1}$ Tumur-Ochir Ganjiguur, ${ }^{2}$ Mohamed AM AboEllail, ${ }^{3}$ Nobuhiro Mori, ${ }^{4}$ Toshiyuki Hata
}

\begin{abstract}
We present our first experience using HDliveFlow with the HDlive silhouette mode for the diagnosis of a persistent right umbilical vein (PRUV) and single umbilical artery (SUA) in a fetus at 28 weeks and 5 days of gestation. Two-dimensional color Doppler showed a single left umbilical artery around the bladder, and PRUV originating from the umbilical cord. HDliveFlow with the HDlive silhouette mode clearly demonstrated SUA and PRUV, and the spatial connection of PRUV to the inferior vena cava through the ductus venosus was detected. The course of the fetal intra-abdominal vasculatures was clarified in detail. Moreover, visualization of the anatomical landmarks, such as the spine was possible using the HDlive silhouette mode. This technique might be a beneficial adjunctive tool for diagnosing fetal peripheral vascular anomalies with advantages over the use of conventional color Doppler alone.
\end{abstract}

Keywords: Fetus, HDliveFlow, HDliveFlow silhouette mode, Persistent right umbilical vein, Single umbilical artery.

How to cite this article: Ganjiguur TO, AboEllail MAM, Mori N, Hata T. HDliveFlow with HDlive Silhouette Mode for Diagnosis of Persistent Right Umbilical Vein and Single Umbilical Artery. Donald School J Ultrasound Obstet Gynecol 2018;12(1):1-3.

Source of support: Nil

Conflict of interest: None

\section{INTRODUCTION}

A PRUV is a fetal vascular developmental anomaly with an estimated prevalence of 2 per 1,000 live births. ${ }^{1}$ It includes the persistence of an open right umbilical vein while the left vein is occluded. ${ }^{2,3}$ It is usually associated with other anomalies, such as an SUA and cardiovascular defects. ${ }^{2,4}$ The prognosis is good in isolated PRUV cases. ${ }^{1-3}$ There have been numerous reports on the prenatal diagnosis of PRUV using two-/three-dimensional (2D/3D) power Doppler sonography; ${ }^{1,3-8}$ however, to the best of

\footnotetext{
${ }^{1}$ Research Fellow, ${ }^{2,3}$ Assistant Professor, ${ }^{4}$ Professor and Chairman

${ }^{1-4}$ Department of Perinatology and Gynecology, Kagawa University Graduate School of Medicine, Kagawa, Japan

Corresponding Author: Toshiyuki Hata, Professor and Chairman, Department of Perinatology and Gynecology, Kagawa University Graduate School of Medicine, Kagawa, Japan, Phone: +810878912174, e-mail: toshi28@med.kagawa-u.ac.jp
}

our knowledge, the use of HDliveFlow with the HDlive silhouette mode for the prenatal diagnosis of PRUV and SUA has not been reported.

\section{CASE REPORT}

A 27-year-old pregnant Japanese primigravida was referred to our ultrasound clinic at $26+1$ weeks' gestation because of a suspected dilated fetal right atrium. At $28+5$ weeks, 2D sonography showed dilatation of the right atrium with tricuspid regurgitation, a persistent left superior vena cava (PLSVC), suspected ventricular septal defect (VSD), and small stomach. The 2D color Doppler revealed a single left umbilical artery around the bladder (Fig. 1A), and PRUV (Fig. 1B). HDliveFlow with the HDlive silhouette mode (Voluson E10, GE Health care Japan, Tokyo, Japan) clearly demonstrated the spatial relationships among PRUV, intra-abdominal vessels, and SUA (Fig. 2).

At $37+5$ weeks' gestation, a cesarean section was performed because of a nonreassuring fetal heart rate pattern, resulting in a female neonate weighing 2,254 gm with a height of $44 \mathrm{~cm}$. Postnatal examination confirmed the presence of SUA and PRUV. The neonatal echocardiography showed the presence of a mildly hypoplastic left ventricle, membranous VSD, and PLSVC, esophageal atresia type III was also identified, and an operation was performed on day 6.

\section{DISCUSSION}

The 2D sonography is the standard method for the prenatal diagnosis of PRUV. The umbilical vein passes laterally and to the right side of the gallbladder, where it connects to the right portal vein. Then, the left curvature of the umbilical vein to the stomach is detected instead of the classic right-side curve. ${ }^{7}$ This topography is usually easily visible in the section obtained to measure the abdominal circumference. The 2D color Doppler is suitable for determining the layout, size, and structure of the umbilical vein and portal venous system. PRUV has two types: intra- and extrahepatic. The intrahepatic type is the most common, occurring in $95 \%$ of cases, ${ }^{3}$ while the remaining cases are of the extrahepatic type. ${ }^{4}$ Recent advanced technologies for 3D/four-dimensional 

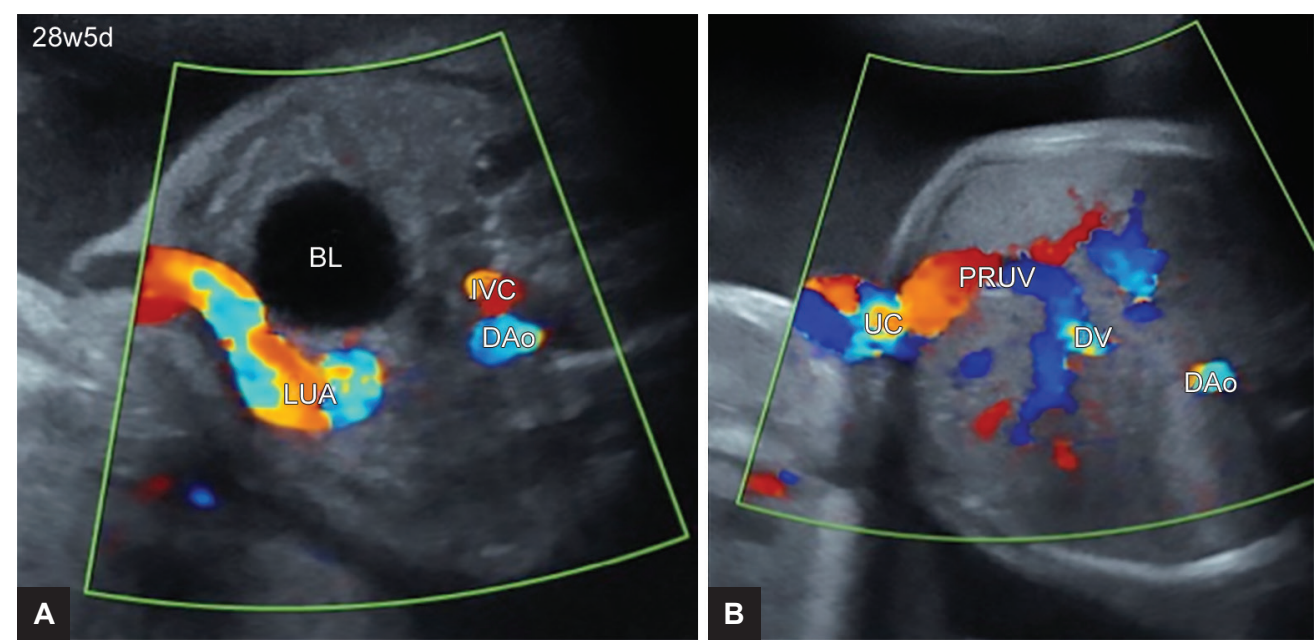

Figs $1 \mathrm{~A}$ and $\mathrm{B}$ : Fetal 2D color Doppler sonographic images at 28 weeks and 5 days of gestation. A left single umbilical artery (SUA) is identified around the bladder (BL) (A). The origin of the PRUV from the umbilical cord (UC) and its connection with the ductus venosus (DV) are shown (B). DAo: Descending aorta; IVC: Inferior vena cava; LUV: Left umbilical artery
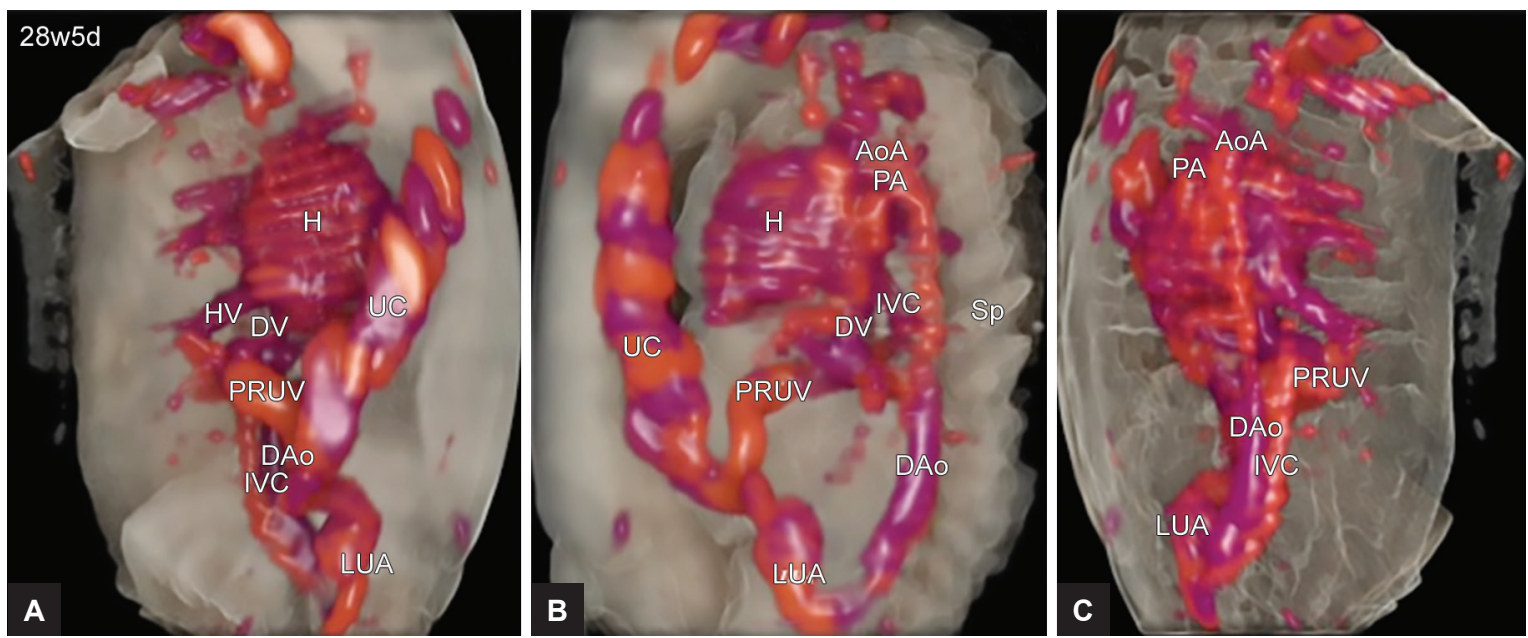

Figs 2A to C: HDliveFlow with HDliveFlow silhouette mode images at 28 weeks and 5 days of gestation. Spatial relationships among great arteries and veins as well as the heart $(\mathrm{H})$ can be clearly seen. A single left umbilical artery (LUA) is visualized. A PRUV originating from the umbilical cord (UC) and its connection to the inferior vena cava (IVC) through the ductus venosus (DV) can be easily noted. The spine (Sp) as anatomical landmark is also demonstrated. AoA: Aortic arch; Dao: Descending aorta; HV: Hepatic vein; PA: Pulmonary artery; (A) anterior view; (B) left lateral view; (C) posterior view

ultrasound, such as HDliveFlow, can clearly demonstrate fetal and placental circulations ${ }^{9-13}$ as well as gynecological disorders. ${ }^{14-18}$ In the present case, conventional color Doppler clearly showed SUA and PRUV. However, HDliveFlow with the HDlive silhouette mode enabled clear detection of the detailed course of the fetal intraabdominal vasculatures, and a better understanding of the spatial relationships among them.

Although the diagnosis was not changed by the use of these techniques, a better understanding of the vascular connections and spatial relationships among them was obtained, and these techniques facilitated identification of the intrahepatic subtype of PRUV. Moreover, the visualization of anatomical landmarks, such as the spine represented a key advantage of this technique. Therefore,
HDliveFlow with the HDlive silhouette mode might be a beneficial adjunctive tool for diagnosing fetal peripheral vascular anomalies with potential advantages over the use of conventional 2D color Doppler alone.

Limitations of this technique are the required learning curve and necessity of fully understanding the anatomy before it can be successfully applied. Further studies involving various fetal vascular anomalies are needed to clarify the true benefits of this technique compared with conventional fetal 2D Doppler imaging.

\section{REFERENCES}

1. Wolman I, Gull I, Fait G, Amster R, Kupferming MJ, Lessing JB, Jaffa AJ. Persistent right umbilical vein: incidence and significance. Ultrasound Obstet Gynecol 2002 Jun;19(6):562-564. 
2. Lide B, Lindsley W, Foster MJ, Hale R, Haeri S. Intrahepatic persistent right umbilical vein and associated outcomes: a systematic review of the literature. J Ultrasound Med 2016 Jan;35(1):1-5.

3. Martinez R, Gamez F, Bravo C, Sanchez P, Orizales C, Ortiz L, De Leon-Luis J. Perinatal outcome after ultrasound prenatal diagnosis of persistent right umbilical vein. Eur J Obstet Gynec Reprod Biol 2013 May;168(1):36-39.

4. Weichert J, Hartge D, Germer U, Axt-Fliedner R, Gembruch U. Persistent right umbilical vein: a prenatal condition worth mentioning? Ultrasound Obstet Gynecol 2011 May;37(5): 543-548.

5. Yang PY, Wu JL, Yeh GP, Chou PH, Hsu JC, Hsieh CT. Prenatal diagnosis of persistent right umbilical vein using three-dimensional sonography with power Doppler. Taiwan J Obstet Gynecol 2007 Mar;46(1):43-46.

6. Sciaky-Tamir Y, Cohen SM, Hochner-Celnikier D, Valsky DV, Messing B, Yagel S. Three-dimensional power Doppler (3DPD) ultrasound in the diagnosis and follow-up of fetal vascular anomalies. Am J Obstet Gynecol 2006 Jan;194(1): 274-281.

7. Shen O, Tadmor OP, Yagel S. Prenatal diagnosis of persistent right umbilical vein. Ultrasound Obstet Gynecol 1996 Jul;8(1):31-33.

8. Leal DB, Maggiolini M, Bianchi A. Prenatal diagnosis and postnatal follow-up of patient with persistent right umbilical vein. Donald School J Ultrasound Obstet Gynecol 2012 Jan-Mar;6(1):104-108.

9. AboEllail MA, Kanenishi K, Tenkumo C, Kawanishi K, Kaji T, Hata T. Diagnosis of truncus arteriosus in first trimester of pregnancy using transvaginal four-dimensional color Doppler ultrasound. Ultrasound Obstet Gynecol 2015 Jun;45(6):759-760.

10. AboEllail MA, Kanenishi K, Tenkumo C, Mori N, Katayama T, Koyano K, Kusaka T, Hata T. Four-dimensional power Doppler sonography with the HDlive silhouette mode in antenatal diagnosis of a right aortic arch with an aberrant left subclavian artery. J Ultrasound Med 2016 Mar;35(3):661-663.

11. Yang PY, Sajapala S, Yamamoto K, Mori N, Kanenishi K, Koyano K, Kusaka T, Hata T. Antenatal diagnosis of idiopathic dilatation of fetal pulmonary artery with 3D power Doppler imaging. J Clin Ultrasound 2017 Feb;45(2):121-123.

12. Tenkumo $C$, Hanaoka $U$, AboEllail MA, Ishimura M, Morine $M$, Maeda K, Hata T. HDlive silhouette mode in diagnosis of fetal hepatic hemangioma. Ultrasound Obstet Gynecol 2017 Apr;49(4):541-542.

13. Ito M, AboEllail MAM, Yamamoto $K$, Kanenishi $K$, Tanaka $H$, Masaoka H, Hata T. HDlive Flow silhouette mode and spatiotemporal image correlation for diagnosing congenital heart disease. Ultrasound Obstet Gynecol 2017 Sep;50(3):411-415.

14. AboEllail MA, Ishimura M, Sajapala S, Yamamoto K, Tanaka K, Nitta E, Kanenishi K, Hata T. Three-dimensional color/ power Doppler sonography and HDlive silhouette mode for diagnosis of molar pregnancy. J Ultrasound Med 2016 Sep;35(9):2049-2052.

15. Yamamoto K, AboEllail MA, Ito M, Mori N, Kanenishi K, Tanaka H, Hata T. HDlive imaging in diagnosis of uterine artery pseudoaneurysm during pregnancy. Ultrasound Obstet Gynecol 2016 Jul;48(1):127-128.

16. Sajapala S, AboEllail MA, Tanaka T, Nitta E, Kanenishi K, Hata T. Three-dimesional power Doppler with silhouette mode for diagnosis of malignant ovarian tumors. Ultrasound Obstet Gynecol 2016 Dec;48(6):806-808.

17. Tanaka T, AboEllail MA, Ishimura M, Yamamoto $K$, Ishibashi M, Mori N, Kanenishi K, Hata T. HDlive Flow with HDlive silhouette mode for diagnosis of malignant tumors of uterine cervix. Donald School J Ultrasound Obstet Gynecol 2016 Jan;10(4):409-412.

18. Yamamoto K, AboEllail MA, Ishimura M, Tanaka T, Mori N, Kanenishi K, Hata T. HDlive silhouette inversion mode in diagnosis of complete hydatidiform mole. J Ultrasound Med 2017 Apr;36(4):833-835. 